\title{
Niche breadth and overlap of spotted deer and domestic cattle with swamp deer in tropical region of Nepal
}

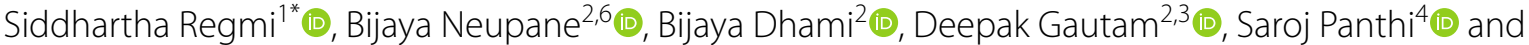 \\ Megharaj Poude $\left.\right|^{5}$ (1)
}

\begin{abstract}
Background: Knowledge about the niche overlap among wild species and domestic cattle is helpful to conserve and manage wildlife. We assessed the habitat niche breadth and overlap of sympatrically living spotted deer (Axis axis) and domestic cattle with swamp deer (Cervus duvaucelii) in Shuklaphanta National Park, Nepal during the dry season to explore the possibility of interspecific competition by studying the habitat use by these species. The assumption was made that the presence of pellets is proof of habitat used by species.

Methods: Grids of $2 \mathrm{~km} \times 2 \mathrm{~km}$ have four subgrids, each with four sample plots, making a total of 16 plots $(20 \mathrm{~m} \times 20 \mathrm{~m})$ in each grid. The size of each sub-grid was $200 \mathrm{~m} \times 200 \mathrm{~m}$ and they were placed randomly inside the grid but at least $1 \mathrm{~km}$ apart from one another. The data was collected in a 96 plots in total. Levin's niche breadth and Morisita's overlap index were calculated to determine the niche breadth and the habitat overlap, respectively.

Results: The Levin's measure of niche breadth suggested that spotted deer had the highest acclimatization with an index value of 0.94 , followed by domestic cattle at 0.50 , and swamp deer at 0.33 in our study area. Thus, our findings supported the evidence that spotted deer are habitat generalists, whereas swamp deer are habitat specialists. The swamp deer had lower niche breadth and more overlap with domestic cattle.

Conclusion: Our study showed the least niche breadth of swamp deer in comparison to spotted deer and domestic cattle. The domestic cattle had the highest and least niche overlap with spotted deer and swamp deer, respectively, in terms of habitat use. Our study suggests that domestic cattle grazing should be stopped, and grassland management should be carried out for the benefit of ungulates. Similar studies should be conducted, including different seasons and places, prior to appropriate habitat management. In addition, further studies are needed to quantify the extent of interspecific competition by incorporating more species.
\end{abstract}

Keywords: Generalist, Levin's niche breadth, Morisita's overlap index, Spatial overlap, Habitat specialist

\section{Background}

Distinctive resource utilization enables different species to concentrate in ecological niches and, as a result, coexist in a distinct zone, and this theory has fueled one of ecology's most productive fields (Chase and Leibold

\footnotetext{
*Correspondence: iregmisid@gmail.com

${ }^{1}$ Institute of Forestry, Tribhuvan University, 44107 Hetauda, Nepal Full list of author information is available at the end of the article
}

2003). When multiple species coexist, biotic interactions (such as competition, predation, parasitism, and mutualism) have an impact on their fitness and behavior, as well as their habitats (Pearson and Dawson 2003). Niche overlap analysis comprises analyzing the use patterns of many dimensions, such as food, habitat, time, and space. However, in this study, we only considered two dimensions, habitat and space, and evaluated the overlap between the species in these dimensions. Inspecting multiple species 
allows us to assess the degree of niche overlap between them (Warren et al. 2010). Similar sympatric species are expected to exhibit niche overlap and competitive interactions in situations of limited resources, both morphologically and phylogenetically (Schoener 1974; Putman 1996). As a consequence, likely competing allopatric species are anticipated to broaden niche distinctions to keep away from or lower competition (Pianka 1974; Schoener 1974; Putman 1996). The spatial facet of a niche (habitat) is the typically split resource accompanied by food (Schoener 1974, 1983; Toft 1985). Niche theory and habitat selection illustrate that akin species with akin niches need to be allopatric or own a number of their behavioral facets that separate them temporally or spatially within the same horizon. Due to resource partitioning, the co-occurrence of competitive species coexists in the same habitat (Hardin 1960). Niche breath can be gained by recognizing individual species' positions within a collection of resource states. A few plants and animals are more specialized than others, and the measure of niche breadth tries to measure this quantitatively. In Nepal, the swamp deer are confined to Shuklaphanta National Park (SNP) and Bardia National Park (BNP), and domestic cattle and other wild ungulates also use their habitat in SNP. Niche breadth and habitat overlap studies will help to explore the factors associated with the habitat of swamp deer in the SNP.

Despite SNP and BNP in Nepal, swamp deer (Cervus duvaucelii) can be found in India's national parks including LaggaBagga, Krishnapur, and Dudhwa (Duckworth et al. 2015b). It has been enlisted as "vulnerable" in the red list of the International Union for Conservation of Nature (IUCN) (Duckworth et al. 2015b) and is listed in Appendix I of the Convention on International Trade in Endangered Species of Wild Fauna and Flora (CITES), which is a treaty that governs the international trade in endangered species (CITES 2019). Among 27 protected species of mammals in Nepal, swamp deer are strictly protected under the National Parks and Wildlife Conservation Act 2029 (1973). It is kept in this category as the only remaining isolated populations of these species are found in small patches within a few areas of Nepal and the government is aiming to establish a sustainable, viable population of these species. Moreover, it is strictly protected because of its heavy habitat loss and poaching, and it is also illegally traded in national and international markets for meat, antlers, and skin (DNPWC 2019). During the 1960s, swamp deer were wiped out from Chitwan National Park, perhaps due to serious factors (such as killing, wildlife disease, and habitat fragmentation and loss) (Duckworth et al. 2015b). Predation, poaching, and flooding are the major reasons for the high mortality of swamp deer (Rucervus $d$. ranjitsinhii and $R$. $d$. duvaucelii) (Duckworth et al. 2015b). This deer is a major prey of the Bengal tiger (Panthera tigris tigris) and there are few reports of kills by common leopards (P. pardus) and dhole (Cuon alpinus) (Qureshi et al. 2004). Swamp deer are principally grazers (Qureshi et al. 2004). Meanwhile, $R . d$. duvaucelii is occasionally reported to feed on aquatic plants, and, $R$. d. ranjitsinhii is found to feed aquatic plants during both monsoon and winter seasons (Qureshi et al. 1994). Spotted deer (Axis axis) have been listed as the "least concern" on the IUCN's red list (Duckworth et al. 2015a). Spotted deer are plastic species, capable of considerable adaptive response. This trait is well reflected in its widespread distribution in India, even where it is considered an exotic species (Dave 2008). In addition, most of the natural ranges of spotted deer are shared with livestock (Dave 2008).

In SNP, livestock induces incessant pressure on native wild herbivores, such as swamp deer (Ottichilo et al. 2000), and therefore, this study is designed to explore the niche overlap of swamp deer with spotted deer and domestic cattle in the food deficient season. Domestic cattle grazing, along with intensifying human pressure are the main problems in the SNP (Bhattarai 2012). The nutritional stability of wild species might be affected by cattle grazing and several disruptions as they expend additional vitality moving elsewhere from the disruptions and can be compelled to forage in poor quality habitat patches and, as a consequence, may be competitively eliminated from high quality habitats (Schaller 1977). Quantitative research on those elements is required with the intention of recognizing the relationships between livestock and herbivores, which can be vital to understanding the important factors limiting wild ungulate densities and formulating a significant conservation plan for the area and the species.

SNP is home to South Asia's largest population of swamp deer, an endemic, restricted, and prone to extinction grassland species (Poudel 2007). Similarly, spotted deer contribute the highest proportion of the diet of tiger species in Nepal (Upadhyaya et al. 2018) that mostly prefer grassland habitats (Sharma and Chalise 2014). The densities of spotted deer and swamp deer are the highest among the other deer species in the park (Pokhrel and Thapa 2008; Karki et al. 2015). Several plans are in progress to translocate some individuals of Swamp deer from SNP to foster the mini population of BNP (Duckworth et al. 2015a, b). In addition, the Department of National Parks and Wildlife Conservation is also studying the feasibility of reintroducing the species to Chitwan National Park (CNP) (Duckworth et al. 2015a, b). Other species such as hog deer are not considered because of a distinctly lower density than that of spotted deer in the park (Adhikari and Thapa 2013). Lamichhane et al. (2020) 
found blue bull evidence in the forest edge, semi-open habitat with dispersed forest patches, and agriculture land across the buffer zone, but not in grassland patches in the core area of the SNP. During the field survey, there was a presence of pellets of ungulates, such as hog deer, blue bull, barking deer, wild boar, etc., but only in a very few sample plots (8 sample plots, i.e., $8.3 \%$ ), which were almost negligible and thus were not a focus for our study either. This study was conducted in the dry/winter season, a food-deficient season. During food deficient conditions, there can be more overlap in the resource use among the wild herbivores and domestic cattle that results in competition (Voeten and Prins 1999). Thus, this study assessed the niche breadth regarding habitat use by the species, assessed the habitat overlap among wild and domestic herbivores, and explored whether the potential exists for direct interspecific competition.

\section{Methods}

\section{Study area}

This study was conducted in the SNP of Nepal, which lies in the far western part of the country and covers an area of $305 \mathrm{~km}^{2}$ with an additional buffer zone area of $243 \mathrm{~km}^{2}$ (SNP 2017) (Fig. 1). Abandoned agricultural land accounts for $7.87 \%$ of the total, with forest accounting for $65.02 \%$, grassland accounting for $16.10 \%$, shrub land accounting for $3.76 \%$, and water bodies accounting for $7.25 \%$ (NTNC 2017). The SNP possesses the largest patch of grassland in Nepal, covering an area of $54 \mathrm{~km}^{2}$, called the Shuklaphanta grassland. Most of the park area is covered with Shorea robusta forest. The major wild prey species of tiger in SNP are barking deer (Muntiacus vaginalis), blue bull (Boselaphus tragocamelus), hog deer (Axis porcinus), rhesus macaque (Macaca mulata), spotted deer, swamp deer, and wild pig (Sus scrofa) (DNPWC 2016; NTNC 2017; Sharma et al. 2020).

\section{Field methods and data collection}

In November, preliminary field surveys and discussions with key informants such as park staff and wardens were conducted to gain information about the different habitat types present in the SNP. During the preliminary field survey, GPS location points of different habitat types were taken and they were plotted in Google Earth Pro and ArcGIS to ensure the grid of $2 \mathrm{~km} \times 2 \mathrm{~km}$ that could be laid out at that location. Habitat types were classified based on the various climax vegetation types present in an area (Pfister and Arno 1980). Data was

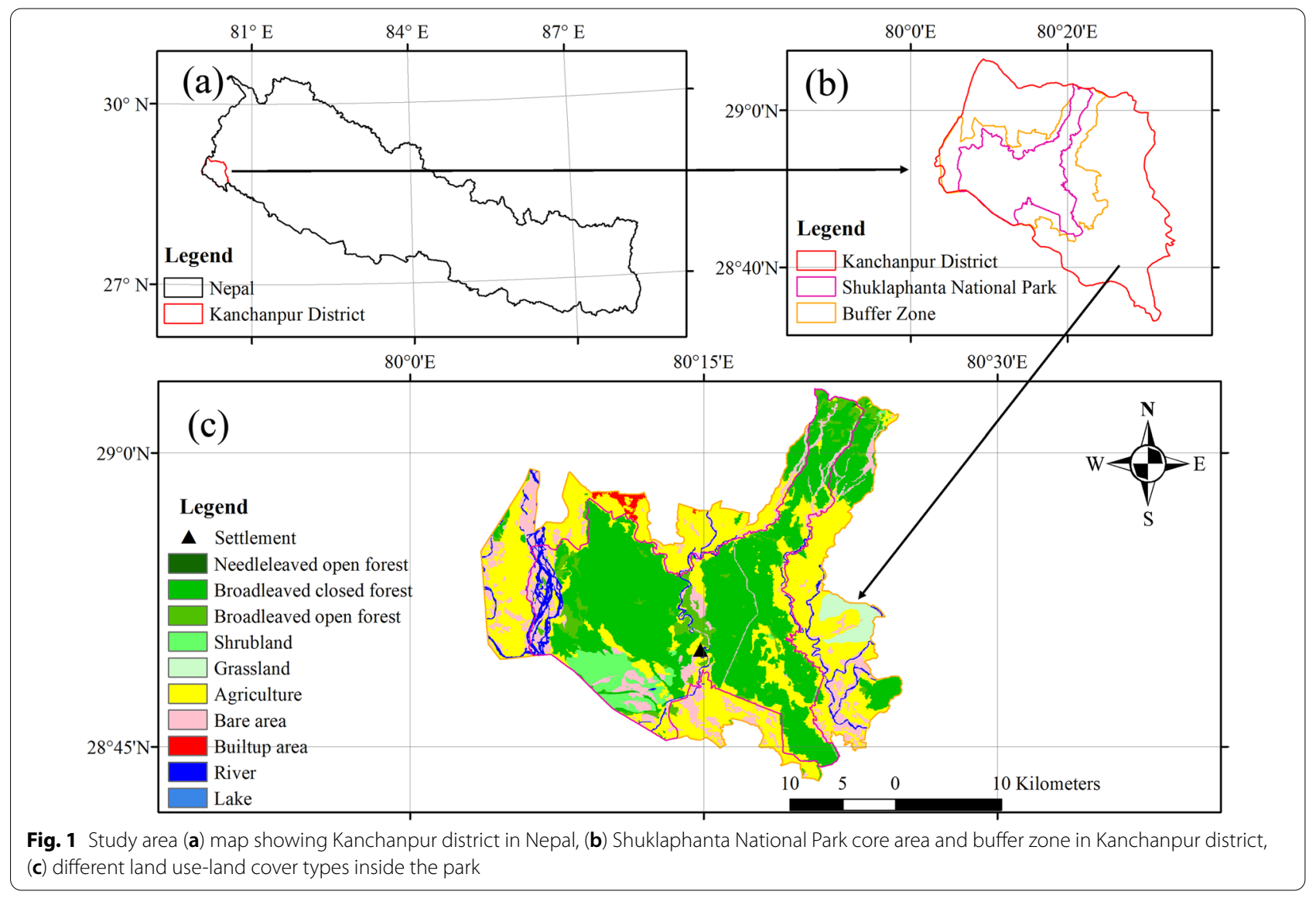


collected during the dry season (November 2018 to February 2019). Field surveys were conducted between 10:00 and 17:00 and the dry season was selected for the study, because the habitat overlap become maximum in the dry season/winter season due to scarce food resources (Arsenault and Owen-Smith 2002). A grid-based survey with a total of 96 sample plots in different habitat types such as open and closed Shorea robusta forest, short grassland, tall grassland, riverine forest, grassland in floodplains, and grassland after fire was assigned and surveyed with an approximately equal number of plots in each habitat type. Different habitat types are also listed in Table 1. In accordance with the main focused species in this study, 96 sample plots and, correspondingly, spatial coverage by plots were assumed to be the most representative for collecting our desired information. In addition, we assumed the occasional turnover of deer species in a negligible number of plots in this time frame of 2 months. The sample grids to be surveyed were fixed, and the grids were selected based on factors such as whether they represent all habitat types present in SNP, the presence of species under consideration, and accessibility. Besides, the sample grids were chosen so that there was no existing fencing measure embraced adjacent, which could directly influence our data and hence the results of research. The representation of all habitat types, the occurrence of focused species and accessibility were also reconfirmed through consultations with park staff, plotting the grids in Google Earth Pro and through ArcMap shapefiles of different habitat types provided by the national park office.

Evans (1979) found that quadrat sampling of fresh pellets was one of the most effective methods for studying ungulate habitat preferences. With the help of ArcGIS, the park was divided into grids of $2 \mathrm{~km} \times 2 \mathrm{~km}$, each with four sub-grids, each with four sample plots, for a total of 16 plots $(20 \mathrm{~m} \times 20 \mathrm{~m})$ in each grid. The size of each sub-grid was $200 \mathrm{~m} \times 200 \mathrm{~m}$ and they were placed randomly inside the grid but at least $1 \mathrm{~km}$ apart from one another. In each sub-grid, a square sample plots of size $20 \mathrm{~m} \times 20 \mathrm{~m}$ was allocated through systematic sampling and was equally spaced with $100 \mathrm{~m}$ of distance in between them (Fig. 2). The layout of the grids is also shown in Fig. 2f. Sample plots with GPS coordinates extracted from ArcGIS were located with the help of handheld GPS devices. On four consecutive days in December, all of the pellets and dung in each sample plot were removed using a clearance method (Putman 1984).

Jung and Kukka (2016) reported that the decay of pellets is more rapid in drier territory than in wet territory due to their acquaintance with sunlight and wind, and also documented that the majority of the pellets fall off after the first growing season (4 months since the deposition of the pellet). Taking these things into consideration, direct field observation was done at a regular 15-day interval in the months of January and February to monitor the cleared sample plots. A field period of 2 months was expected to be appropriate in tropical humid climatic regions, and taking more months could have caused loss of pellets due to factors, such as rain, wind, human trampling, fire, etc. A group of three team members familiar with the wildlife species of the study area and with good knowledge of identifying pellets of different species were involved throughout the field survey. Only fresh pellets were thoroughly searched inside all the laid sample plots of size $20 \mathrm{~m} \times 20 \mathrm{~m}$, since all the old pellets were cleared previously. During the observations, pellets were identified and noted on the survey sheet.

No camera trapping or other sophisticated genetic analysis was used to gather the information on niche

Table 1 Niche breadth

\begin{tabular}{llll}
\hline Habitat types & \multicolumn{2}{l}{ Number of plots in which species signs occurred } & Domestic cattle \\
\cline { 2 - 4 } & Spotted deer & Swamp deer & 4 \\
\hline Closed Shorea forest & 11 & 0 & 9 \\
Open Shorea forest & 13 & 1 & 2 \\
Riverine forest & 14 & 1 & 4 \\
Short grassland & 10 & 3 & 0 \\
Tall grassland & 13 & 4 & 0 \\
Grassland after fire & 8 & 2 & 5 \\
Grassland in floodplains & 7 & 23 & 24 \\
Total & 76 & 3.02 & 4.05 \\
Levin's Niche Breadth & 6.65 & 0.33 & 0.50 \\
Standardized Levin's Niche breadth & 0.94 & 2 \\
\hline
\end{tabular}

This table shows the number of plots in which the focused species signs were found in different habitats present in SNP and the calculated niche breath. Spotted deer had the highest niche breadth 


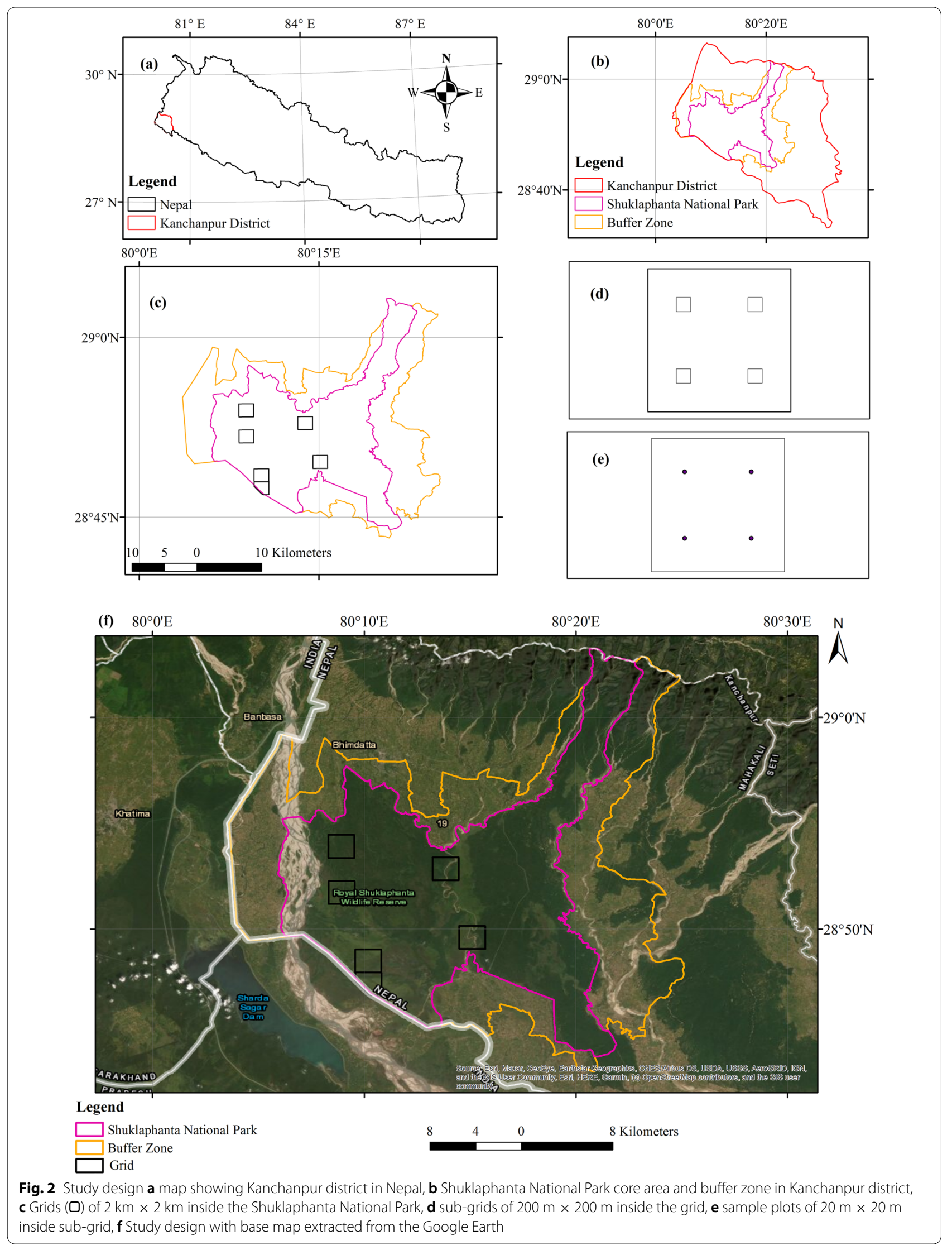


dimensions (habitat use and space) as the pellet count method can also easily govern the areas used intensively by faunas (Julander 1958) and a similar method was used in several other studies (Bailey and Putman 1981; Putman 1984; Hemami et al. 2005). Likewise, pellets of the different species were distinguished from each other by their size and shape following Rivero et al. (2005) and also with the assistance of veteran local field assistants.

\section{Data analysis}

Based on the equation given below (Krebs 1999), Levin's measure of niche breadth was calculated for all species under study:

$$
\begin{aligned}
& B=\frac{1}{\sum P i^{2}} \\
& B^{\prime}=\frac{B-1}{n-1}
\end{aligned}
$$

where $B=$ Levin's measure of niche breadth, $B^{\prime}=$ Standardized niche breadth, $p_{i}=$ Proportion of individuals found in or using resource state $i, n=$ number of possible resource state.

The percentage of cover overlap between species pairs or spatial overlap was determined by knowing the number of plots shared by species in the sample grids. Then Morisita's index was used to determine the resource overlap between the pair of species, as described in Krebs (1999). The index values range from 0 to 1 . "Zero" represents no overlap, whereas "one" represents maximum overlap. High overlap (0.80), moderate overlap (0.400.80 ), and low overlap $(0.40)$ were defined as the three levels of overlap (Jung et al. 2015):

$$
\begin{gathered}
c=\frac{2 \sum_{i}^{n} p_{i j} p_{i k}}{\sum_{i}^{n} p_{i j}{ }^{\frac{\left(n_{i j}-1\right)}{\left(N_{j}-1\right)}}+\sum_{i}^{n} p_{i k}{ }^{\frac{\left(n_{i j}-1\right)}{\left(j_{j}-1\right)}}} \\
\sum_{i=1}^{n} n_{i j}=N_{j} ; \sum_{i=1}^{n} n_{i k}=N_{k}
\end{gathered}
$$

where $c=$ Morisita's index of niche overlap between species $j$ and $k, p_{i j}=$ proportion resource $i$ is of the total resources used by species $j, p_{i k}=$ proportion resource $i$ is of the total resources used by species $k, n_{i j}=$ number of individuals of species $j$ that use resource category $i$, $n_{i k}=$ number of individuals of species $k$ that use resource category $i, N_{j}, N_{k}=$ total number of individuals of each species in the sample.

\section{Results}

Seven habitat types were found in the SNP, including forest and grassland. They are closed Shorea forest, open Shorea forest, or Shorea savana, riverine forest, short grassland, tall grassland, grassland after fire, and floodplain grassland. Through the pellet counts from the gridbased sampling during the dry season, Levin's measure of niche breadth or adaptability showed that spotted deer had the highest adaptability with an index value of 0.94 , followed by domestic cattle at 0.50 , and swamp deer at 0.33 in SNP (Table 1).

The co-occurrence of swamp deer and spotted deer was observed in $69.50 \%$ of plots in which the presence of swamp deer was recorded. The co-occurrence of domestic cattle and spotted deer was detected in $28.90 \%$ of plots in which the presence of spotted deer was recorded. However, the co-occurrence of domestic cattle and swamp deer in the sample plots was found to be negligible.

During the dry season, domestic cattle have a high Morisita's index of overlap of 0.83 with spotted deer. Spotted deer have a moderate overlap index value of 0.57 with swamp deer, whereas there is a low overlap index value for swamp deer with domestic cattle at 0.23 (Table 2).

Interaction of domestic cattle with wild species is very high in Shorea robusta forest, while there is no interaction in tall grassland and grassland after fire (Fig. 3).

\section{Discussion}

The biggest herd of swamp deer individuals on a global scale is supported by the SNP (Poudel 2007). However, at present, this species is restricted only to the SNP and BNP of Nepal, which has always been at the risk of extinction due to possible disturbances. Based on relevant literature, we have regarded habitat as the major component of the ecological niche for our study (Schoener 1989; Chase and Leibold 2003). This study explored the possibility of interspecific competition of swamp deer with spotted deer and domestic herbivores in SNP through determination of niche breadth and overlap. From our study, we found that swamp deer mostly preferred the grassland formed after a fire, while their next choices were the tall grassland, short grassland, and

Table 2 Morisita's habitat overlap index for different species

\begin{tabular}{llll}
\hline Species & Spotted deer & Swamp deer & Domestic cattle \\
\hline Spotted deer & 1 & 0.57 & $\mathbf{0 . 8 3}$ \\
Swamp deer & 0.57 & 1 & 0.23 \\
Domestic cattle & $\mathbf{0 . 8 3}$ & 0.23 & 1
\end{tabular}

Bold values just highlight the highest habitat overlap index among spotted deer and domestic cattle

Highest habitat overlap index (0.83) was found between domestic cattle and spotted deer 


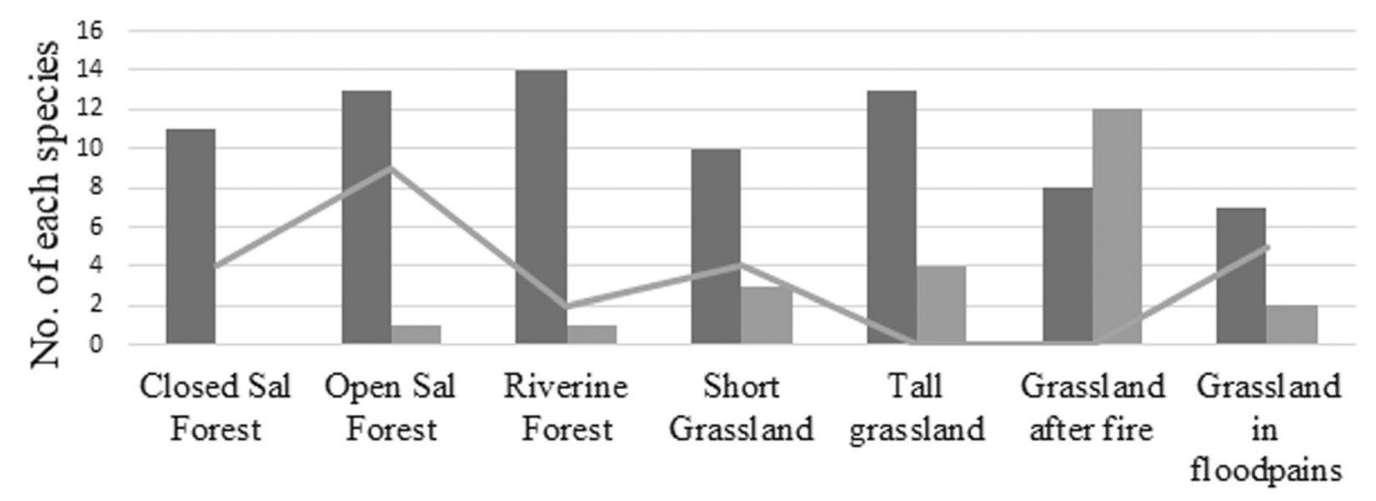

\section{Spotted deer $\square$ Swamp deer $\quad$ Domestic Species}

Fig. 3 Interaction of domestic cattle with wild species in different habitat types. Interaction of domestic cattle with wild species was very high in Shorea robusta forest

grassland located in the floodplain. Its presence is very low in the riverine forest and the Shorea robusta forest. This study is similar to Wegge et al. (2006) as it reports more late successional grasses (Naranga and Themeda spp.) and short grasses (such as Imperata cylindrica) in the diet of swamp deer. In addition, Moe and Wegge (1997) found that cut-and-burned action enhanced the forage quality, resulting in higher deer density, as the deer preferred the burned plots. Similarly, a study conducted in Uttarakhand, India has also reported grasses and herbs as the major diet of swamp deer (Tewari 2013). For these reasons, deer were recorded within the grassland after the fire, where they got new growth of grass as well as the fiery remains, a source of minerals. They adapted to all types of grassland. The spotted deer did not show many differences in the use of different habitat types. This study found that spotted deer mostly occurred in riverine forest, followed by open Shorea forest, tall grassland, and closed Shorea forest. Spotted deer's diet consists of both browse and grass, with the latter contributing much of their nutrition throughout the year (Kushwaha 2016). Despite being recognized as a chief grazer, it sometimes ingests fallen leaves, flowers, and fruits in the drier areas during the winter season (Sankar 1994; Sankar and Acharya 2004; Raman 2013). It co-existed with the domestic species and was prevalent even near human disturbance areas. Domestic cattle were prevalent in grassland in the flood plain and open Shorea forest, followed by short grassland and riverine forest. Thus, there is a chance of competition between the swamp deer and spotted deer in tall grassland and short grassland. Similarly, there is the chance of competition between domestic cattle on short grassland and on flood plains.

Niche breadth is the evenness of the spread of individuals of particular species within the availability of resource conditions (Krebs 1999). This study calculated that Levin's niche breadth was highest for the spotted deer, followed by domestic cattle and swamp deer. Thus, the swamp deer has low distribution among the resource states, but the spotted deer is uniformly distributed in forests and grasslands. The study was quite different from ours, and they found that spotted deer avoided the intense crown cover areas and detected their presence in the open forested sites. However, this discrepancy could be related to differences in vegetation types, since the extensive canopy cover in Pokharel and Storch (2016) was predominantly dominated by Anogeissus latifolia and Terminalia tomentosa, whereas the vegetation in this case is primarily Shorea robusta and Acacia catechu.

Morisita's habitat overlap index found that there was high resource overlap between spotted deer and domestic cattle and that for the spotted deer and swamp deer was moderate, while for swamp deer and domestic cattle it was low. Similar findings were observed in the dietary overlay of cattle and deer in the winter season as well as the occurrence of their competitive interactions (Jenks et al. 1996). However, the spotted deer tries to separate from others by avoiding the mixed forest, anthropogenic disturbances, short grasslands, and predators' presence, particularly during the summer season (Bhattarai 2019). The forest and grassland periphery were the most frequently sighted ecotone areas for this deer species (Schaller 1967; Eisenberg 1981; Bagchi 2001).

Habitat partitioning is a common biological strategy for reducing niche overlap and avoiding competition among co-occurring species (Rosenzweig 1981; Traba et al. 2015). Swamp deer and spotted deer showed habitat partitioning during the dry season. The spotted deer segregated from the short grassland and created a suitable environment for the swamp deer. Similarly, the spotted 
deer creates proper conditions for the swamp deer by consuming the fallen leaves and flowers, though it is chiefly a grazer. The livestock and spotted deer habitat overlap more, and it can create a situation, where spotted deer move to the habitat of swamp deer and create difficulties. Bhatta (2008) reported that swamp deer do not frequently visit the area grazed by livestock. Evidence also suggests that livestock may compete for forage available in the area, and thus deer are forced to forage in areas, where vegetation with less nutritional quality is available (Crawford 1984). However, it should be taken into account that overlap of any or all of the niche dimensions (food, habitat, time, and space) by any two species would not forcibly indicate that there is competition between those species; it would illustrate that there is an association or the likelihood of competition (Holt 1987; Prins and de Boer 1990). However, this study did not explore more about it, so more research on the intensity of competition is required. We just focused on overlap in our study, which will guide further research in the future. According to the field observations and key informant survey from the park authority, there is an increasing trend of domestic cattle grazing inside the park area, so we predict that such conditions will accelerate more competition with the herbivore wild animals feeding on the same plant species.

Based on the information received from park staff and field visits, some of the efforts made by park people to minimize the problem of domestic cattle grazing are mesh wire fencing, electric fencing, intensive patrolling, community awareness, etc. Moreover, various habitat management operations are done in a few areas to reduce the effect of niche and habitat overlap, such as artificial grass cutting with tractors, waterholes with solar water pumps, controlled fires, etc. Likewise, grazing of domestic cattle should be controlled, and the plant species utilized by wild ungulates should be protected and increased to minimize the existing competition. However, detailed studies regarding the diet composition of these competing species in different seasons and other places are suggested to get a clear understanding and information prior to implementing the management activities in the study area.

\section{Conclusions}

Our study showed the least niche breadth of swamp deer in comparison to spotted deer and domestic cattle. This implies that swamp deer are habitat specialists, and they are especially vulnerable if habitat degradation and fragmentation continue in their preferred habitats. The existence of swamp deer was significant in the grasslands after the fire during the dry season. Thus, conservation strategies such as managing grassland with prescribed fire, artificial grass cutting by tractors, enhancing connectivity among priority grassland habitat patches, etc., should be implemented to sustain such an endemic population of swamp deer in the study area. Besides, although there was little overlap between swamp deer and domestic cattle, the domestic cattle and swamp deer had the highest and moderate overlap with spotted deer, respectively, which suggests that the grazing of domestic cattle should be strictly controlled to minimize possible competition with wild ungulates. In addition, further studies are recommended to access the niche breadth using more sophisticated techniques, such as genetic analysis, radio-telemetry, etc.

\section{Abbreviations}

BNP: Bardia National Park; CITES: Convention on International Trade in Endangered Species of Wild Fauna and Flora; DNPWC: Department of National Park and Wildlife Conservation; IUCN: International Union for Conservation of Nature; SNP: Shuklaphanta National Park.

\section{Acknowledgements}

We would like to express profound gratitude to chief warden Laxman Poudel of SNP, Kamal Raj Aryal, Gyanendra Shah, and the whole National Trust for Nature Conservation (NTNC) team, rangers, game scouts, Hattisar staffs and all other staffs for the technical and other support during the data collection.

\section{Authors' contributions \\ SR: conceptualization—lead, data curation_lead, methodology-equal, formal analysis_equal, project administration - lead. BN: conceptualization- equal, formal analysis — equal, writing — review and editing —equal. BD: writ- ing — review and editing —equal. DG: writing — review and editing —equal. SP: writing — review and editing —equal. MP: conceptualization—equal, data curation —equal, formal analysis_equal, writing — review and editing-lead. All authors read and approved the final manuscript.}

\section{Funding}

This research was financially supported by the Ministry of Industry, Tourism, Forest and Environment, Sudurpaschim Province, Nepal. Similarly, we would like to thank IDEA WILD for the instrument support (REGMNEPA0419).

Availability of data and materials

Data will be available on request.

\section{Declarations}

Ethics approval and consent to participate

Not applicable.

Consent for publication

Not applicable.

Competing interests

The authors declare that they have no competing interests.

\section{Author details}

${ }^{1}$ Institute of Forestry, Tribhuvan University, 44107 Hetauda, Nepal. ${ }^{2}$ Institute of Forestry, Tribhuvan University, 33700 Pokhara, Nepal. ${ }^{3}$ School of Ecology and Nature Conservation, Beijing Forestry University, Beijing 100083, China. ${ }^{4}$ Ministry of Forest, Environment and Soil Conservation, Pokhara 33700, Gandaki, Nepal. ${ }^{5}$ Ministry of Forests and Environment, Forest Research and Training Center, Kathmandu 44600, Nepal. ${ }^{6}$ Faculty of Agriculture and Forestry, University of Helsinki, 00014 Helsinki, Finland. 
Received: 31 May 2021 Accepted: 24 January 2022

Published online: 09 February 2022

\section{References}

Adhikari P, Thapa TB (2013) Estimating abundance of large mammalian prey in Suklaphanta Wildlife Reserve, Nepal. J Inst Sci Technol 18(2):84-89

Arsenault R, Owen-Smith N (2002) Facilitation versus competition in grazing herbivore assemblages. Oikos 97(3):313-318. https://doi.org/10.1034/j. 1600-0706.2002.970301.x

Bagchi S (2001) Resource selection and resource partitioning among wild ungulates in the tropical semiarid forest of Ranthambhore National Park, Rajasthan. M.Sc. Thesis

Bailey RE, Putman RJ (1981) Estimation of fallow deer (Dama dama) populations from faecal accumulation. J Appl Ecol 18:697-702. https://doi.org/ $10.2307 / 2402361$

Bhatta B (2008) Daily activities, distribution, and food preference of swamp deer (Cervus duvauceli duvauceli). M.Sc. Thesis. Institute of Forestry, Tribhuvan University, Pokhara, Nepal

Bhattarai P (2012) Threats on grassland ecosystem services: a case from Shuklaphanta Wildlife Reserve, Nepal. J Sci Tech 13(2):159-166. https://doi.org/ 10.3126/njst.v13i2.7729

Bhattarai BP (2019) Factors associated with habitat segregation among the four species of cervids in the Chitwan National Park, Nepal. Ekologia Bratislava 38(1):37-48. https://doi.org/10.2478/eko-2019-0004

Chase JM, Leibold MA (2003) Ecological niche: linking classical and contemporary approaches. Pant Syst Evol 250:259-270. https://doi.org/10.1007/ s00606-004-0254-8

CITES (2019) Appendices I, II and III, convention on international trade in endangered species of wild fauna and flora.

Crawford HS (1984) Habitat management. In: Halls LK (ed) White-tailed deer ecology and management. Stackpole Books, Harrisburg, Pennsylvania, pp 629-646

Dave CV (2008) Ecology of chital (Axis axis) in Gir. Saurashtra University. http:// etheses.saurashtrauniversity.edu/id/902

DNPWC (2016) Annual Report (July 2015-June 2016). Department of National Park and Wildlife Conservation, Kathmandu, Nepal

DNPWC (2019) Annual Report (July 2018-June 2019). Department of National Park and Wildlife Conservation, Kathmandu, Nepal

Duckworth JW, Kumar NS, Anwarul IM, Baral HS, Timmins R (2015a) Axis axis. The IUCN red list of threatened species 2015.e.T41783A22158006. https:// doi.org/10.2305/IUCN.UK.2015-4.RLTS.T41783A22158006.en

Duckworth JW, Kumar NS, Pokharel CP, Baral HS, Timmins R (2015b) Rucervus duvaucelii. The IUCN Red List of Threatened Species. e.T4257A22167675. https://doi.org/10.2305/IUCN.UK.2015-4.RLTS.T4257A22167675.en

Eisenberg JF (1981) The mammalian radiations: an analysis of trends in evolution, adaptation, and behaviour. The Atholone, London, pp 509-599

Evans PGH (1979) Habitat preferences of ungulates in closed savanna of central Africa. Mammal Rev 9(1):19-32. https://doi.org/10.1111/j.1365-2907. 1979.tb00229.x

Hardin G (1960) The competitive exclusion principle. Science. Science 131:1292-1297. https://doi.org/10.1126/science.131.3409.1292

Hemami MR, Watkinson AR, Dolman PM (2005) Population densities and habitat associations of introduced muntjac (Muntiacus reevesi) and native roe deer (Capreolus capreolus) in a lowland pine forest. For Ecol Manage 215:224-238. https://doi.org/10.1016/j.foreco.2005.05.013

Holt R (1987) On the relation between niche overlap and competition: the effect of incommensurable niche dimensions. Oikos 48:110-114. https:// doi.org/10.2307/3565696

Jenks JA, Leslie DM Jr, Lochmiller RL, Melchiors MA, McCollum I (1996) Competition in sympatric white-tailed deer and cattle populations in southern pine forests of Oklahoma and Arkansas, USA. Acta Theriol 41(3):287-306

Julander O (1958) Techniques in studying competition between big game and livestock. J Range Manag 11(1):18-21

Jung TS, Kukka PM (2016) Influence of habitat type on the decay and disappearance of elk Cervus canadensis pellets in boreal forest of northwestern Canada. Wildl Biol 22(4):160-166. https://doi.org/10.2981/wlb.00186

Jung TS, Stotyn SA, Czetwertynski SM (2015) Dietary overlap and potential competition in a dynamic ungulate community in northwestern Canada. J Wildl Manag 79(8):1277-1285. https://doi.org/10.1002/jwmg.946
Karki JB, Barber-Meyer SM, Jhala YV, Pandav B, Jnawali SR, Shrestha R, Thapa K, Thapa G, Pradhan NMB, Lamichane BR, Dhakal M (2015) Estimating the abundance of tigers and their prey in Suklaphanta Wildlife Reserve of Terai Arc Landscape, Nepal. In: Biodiversity Conservation efforts in Nepal: a special issue published on the occasion of 20th Wildlife Week, pp 41-56

Krebs C (1999) Ecological methodology, 2nd edn. Addison Wesley, Menlo Park, California, p 620

Kushwaha PK (2016) Wild ecology of spotted deer (Axis axis). Acad Voices 6(1):21-23. https://doi.org/10.3126/av.v6i0.20103

Lamichhane S, Khanal G, Karki JB, Aryal C, Acharya S (2020) Natural and anthropogenic correlates of habitat use by wild ungulates in Shuklaphanta National Park, Nepal. Glob Ecol Conserv 24:e01338. https://doi.org/10. 1016/j.gecco.2020.e01338

Moe SR, Wegge P (1997) The effects of cutting and burning on grass quality and axis deer (Axis axis) use of grassland in lowland Nepal. J Trop Ecol 13(2):279-292. https://doi.org/10.1017/S0266467400010452

NTNC (2017) Annual Report. Downloaded from https://ntnc.org.np/publi cation/annual-report-2017

Ottichilo WK, De L, Skidmore AK, Prins HH, Said MY (2000) Population trends of large non-migratory wild herbivores and livestock in the Masai Mara ecosystem, Kenya, between 1977 and 1997. Afr J Ecol 38(3):202-216

Pearson RG, Dawson TP (2003) Predicting the impacts of climate change on the distribution of species: are bioclimate envelope models useful? Glob Ecol Biogeogr 12(5):361-371. https://doi.org/10.1046/j.1466-822X.2003. 00042.x

Pfister RD, Arno SF (1980) Classifying forest habitat types based on potential climax vegetation. For Sci 26(1):52-70. https://doi.org/10.1093/forestscie nce/26.1.52

Pianka ER (1974) Niche overlap and diffuse competition. Proc Natl Acad Sci 71(5):2141-2145. https://doi.org/10.1073/pnas.71.5.2141

Pokharel KP, Storch I (2016) Habitat niche relationships within an assemblage of ungulates in Bardia National Park, Nepal. Acta Oecol 70:29-36. https:// doi.org/10.1016/j.actao.2015.11.004

Pokhrel S, Thapa TB (2008) Relative abundance and distribution of wild ungulates in Sukhaphata Wild life Reserve, Nepal. In: Proceedings of Ecocity World Summit, p 12

Poudel BS (2007) Thirty years of managing Shuklaphanta, the swamp deer and the tiger: issues and strategies. Initiation 1:72-76

Prins H, de Boer W (1990) Large herbivores that strive mightily but eat and drink as friends. Oecologia 82:264-274. https://doi.org/10.1007/BF003 23544

Putman RJ (1984) Facts from feces. Mammal Rev 14:79-97. https://doi.org/10. 1111/j.1365-2907.1984.tb00341.x

Putman RJ (1996) Competition and resource partitioning in temperate ungulate assemblies. https://doi.org/10.2307/5954

Qureshi Q, Sawarkar VB, Mathur PK (1994) Ecology and management of Swamp Deer project report. Wildlife Institute of India

Qureshi Q, Sawarkar VB, Rahmani AR, Mathur PK (2004) Swamp deer or barasingha (Cervus duvauceli Cuvier, 1823). Envis Bull 7:181-192

Raman TRS (2013) The Chital (Axis axis Erxleben). The University of Chicago Press, Chicago

Rivero K, Rumiz DI, Taber AB (2005) Differential habitat use by two sympatric brocket deer species (Mazama americana and M. gouazoubira) in a seasonal Chiquitano forest of Bolivia. Mammalia 69(2):169-183. https://doi. org/10.1515/mamm.2005.015

Rosenzweig ML (1981) A theory of habitat selection. Ecology 62(2):327-335. https://doi.org/10.2307/1936707

Sankar K (1994) The ecology of three large sympatric herbivores (chital, sambar, nilgai) with special reference for reserve management in Sariska Tiger Reserve, Rajasthan. PhD Thesis. University of Rajasthan

Sankar K, Acharya B (2004) Spotted deer or chital (Axis axis Erxleben). Ungulates of India. ENVIS Bull Wildl Protect Areas 7(1):171-180

Schaller GB (1967) Indian wildlife. Book reviews: the deer and the tiger. A study of wildlife in India. Science 155:1093

Schaller GB (1977) Mountain monarchs. Wild sheep and goats of the Himalaya. University of Chicago Press, Chicago

Schoener TW (1974) Resource partitioning in ecological communities. Science 185(4145):27-39. https://doi.org/10.1126/science.185.4145.27

Schoener TW (1983) Field experiments on interspecific competition. Am Nat 122(2):240-285. https://doi.org/10.1086/284133 
Schoener TW (1989) The ecological niche. In: Cherret JM (ed) Ecological concepts. Blackwell, Oxford, pp 79-113

Sharma G, Chalise MK (2014) Habitat preference of Spotted Deer (Axis axis) in Ghailaghari Buffer Zone Community Forest, Chitwan, Nepal. Special issue DNPWC-2071

Sharma P, Panthi S, Yadav SK, Bhatta M, Karki A, Duncan T et al (2020) Suitable habitat of wild Asian elephant in Western Terai of Nepal. Ecol Evol 10(12):6112-6119. https://doi.org/10.1002/ece3.6356

SNP (2017) Site specific grassland management guideline for Shuklaphanta National Park. https://doi.org/10.11164/jjsps.8.5_598_3

Tewari R, Rawat GS (2013) Studies on the food and feeding habits of swamp deer (Rucervus duvaucelii duvaucelii) in Jhilmil Jheel Conservation Reserve, Haridwar, Uttarakhand, India. International Scholarly Research Notices

Toft CA (1985) Resource partitioning in amphibians and reptiles. Copeia 1:1-21. https://doi.org/10.2307/1444785

Traba J, Morales MB, Carmona CP, Delgado MP (2015) Resource partitioning and niche segregation in a steppe bird assemblage. Community Ecol 16(2):178-188. https://doi.org/10.1556/168.2015.16.2.5

Upadhyaya SK, Musters CJM, Lamichhane BR, de Snoo GR, Thapa P, Dhakal M, de longh HH (2018) An insight into the diet and prey preference of tigers in Bardia National Park, Nepal. Trop Conserv Sci 11:1-9

Voeten MM, Prins HH (1999) Resource partitioning between sympatric wild and domestic herbivores in the Tarangire region of Tanzania. Oecologia 120(2):287-294

Warren DL, Glor RE, Turelli M (2010) ENMTools: a toolbox for comparative studies of environmental niche models. Ecography 33:607-611. https://doi. org/10.1111/j.1600-0587.2009.06142.x

Wegge P, Shrestha AK, Moe SR (2006) Dry season diets of sympatric ungulates in lowland Nepal: competition and facilitation in alluvial tall grasslands. Ecol Res 21(5):698-706. https://doi.org/10.1007/s11284-006-0177-7

\section{Publisher's Note}

Springer Nature remains neutral with regard to jurisdictional claims in pub-

lished maps and institutional affiliations.

\section{Submit your manuscript to a SpringerOpen ${ }^{\circ}$ journal and benefit from:}

- Convenient online submission

- Rigorous peer review

- Open access: articles freely available online

- High visibility within the field

- Retaining the copyright to your article

Submit your next manuscript at $\boldsymbol{\nabla}$ springeropen.com 